Guest Editorial, part of a Special Feature on Bird Conservation in the Boreal Forest / Conservation des oiseaux de la forêt boréale

\title{
Conservation of Boreal Birds and the Case for Resilience: Does it Pass the
} Test?

\section{Conservation de l'avifaune boréale et résilience écologique: l'hypothèse passe-t-elle le test?}

\author{
$\underline{\text { Fiona K. A. Schmiegelow }}^{1}$ and Marc-André Villard $^{2}$
}

Key Words: boreal birds; forest harvesting; natural disturbance paradigm; range of natural variability; resilience

Enter the keyword "resilience" into a search engine and you will generate an impressive list of nearly half a million scholarly works. Most deal with human dimensions of the concept: societies, their institutions and economies, and the capacity of these systems to deal with disruption and stress. About one in six explores ecological resilience - the ability of an ecosystem to absorb disturbance and maintain structures and functions within a characteristic state or stability domain. An increasing proportion bridge the social-ecological divide by examining the relationships between humans and natural systems, and management feedbacks that may compromise or confer resilience (e.g., Berkes et al. 2003, Walker et al. 2004). Enhanced global recognition and concern about rates of change in natural systems due to human land use, resource consumption, and climate change, and associated impacts on the sustainability of social systems and societal values suggest this trend is likely to continue. Concerns over the simplification of forests and loss of biodiversity are already driving the establishment of new legislation and policies to encourage forest sustainability in many parts of the world (e.g., Young et al. 2005) and the development of more ecologically based forest management systems (Puettmann et al. 2009). In North America, emulating natural disturbance regimes is emerging as the dominant paradigm in forest management for mitigating the undesired effects of anthropogenic activities on forest structure and function, conserving forest biodiversity, and maintaining or restoring ecosystem resilience (Long 2009).

A key element of resilience, and a fundamental construct of natural-disturbance-based management, is the notion of adaptive capacity. A system with greater adaptive capacity will be more resilient to change, and less likely to experience radical shifts in structure or function in response to disturbance; at least, in response to disturbance that falls within the bounds of that experienced historically. Boreal forests are highly dynamic systems characterized by large-scale natural disturbances such as fire and insect outbreaks. It has been hypothesized that boreal biota, due to a coevolved history with an environment that experienced extreme, periodic natural disturbances, may be more resilient to human-induced habitat change than biota in other forested systems; in particular, to disturbance related to timber management. Boreal avifauna provides some support for this idea. For example, a number of studies indicate considerably weaker evidence for local effects of forest fragmentation on boreal birds, such as patch-size-related increases in predation, competition, and nest parasitism than is

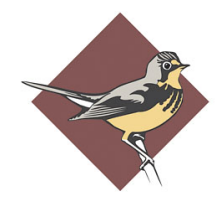

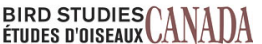


observed in bird populations in temperate systems (reviewed by Schmiegelow and Mönkkönen (2002)). Nevertheless, there exist key uncertainties about to what extent habitat change affects boreal birds, at what scales, and why. Given an increased focus on large-scale developments throughout boreal forests of North America, and the significance of these systems to continental bird populations (Blancher 2003), we launched a special section of $A C E-E C O$ to focus attention on the "resilience hypothesis" and its application to bird conservation in boreal forests.

Testing the resilience hypothesis with respect to forest management is not a trivial exercise (Drever et al. 2006). Ideally, it requires the comparison of naturally disturbed areas with areas subject to forest management plans and operations inspired by understanding of natural disturbance regimes. The spatial and temporal scales over which to evaluate the response of the system, or components of the system, must be considered, as well as the appropriate reference state (Carpenter et al. 2001, Beisner et al. 2003). In forests, vegetation succession following natural disturbance creates changes in conditions, but from the standpoint of ecosystem resilience, does not necessarily reduce stability or represent an alternate state. However, management activities that alter successional pathways or the duration of different successional stages may result in significant changes in the structure and composition of communities, such that resilience is compromised. Finally, because the hypothesis implies differential adaptation by species to contrasting natural disturbance regimes, a full evaluation would also include a comparison of bird community or population parameters drawn from forest regions with different disturbance histories (e.g., Bélisle et al. 2007). Unfortunately, our ability to evaluate resilience in this context is constrained by the availability of suitable areas (only recently have serious attempts been made to emulate natural disturbance through forest management), and the existence of data of sufficient spatial and temporal extent, collected using similar protocols. Most boreal bird studies are local and relatively short in duration, and were not established with spatial stratification of disturbance regimes in mind.

In the absence of ideal conditions, and recognizing that conservation policy and management strategies must still be developed for boreal forests, it is possible to explore the resilience hypothesis by contrasting the response of boreal avifauna to stand, landscape, or regional habitat features associated with natural vs. anthropogenic disturbances. In this spirit, we highlight the contributions of six papers published in recent issues of $A C E-E C O$ as part of this special section. The papers cover a broad geographic extent-from the boreal mixedwood forests of Alberta to the wet spruce-fir forests of Newfoundland-and examine both pattern and process in individual-, population-, and communitylevel responses. Collectively, they highlight the potential of applying natural disturbance-based management as an approach to support the conservation of boreal birds in managed landscapes, but also the pitfalls of assuming resilience in the face of notable differences in response between areas subjected to natural and anthropogenic disturbances. The studies also yield important insights into boreal bird ecology and suggest fruitful directions for future research, as well as key considerations in the development of conservation policy.

The first set of companion papers in the special section develops and applies an avifaunal "bioassay" for evaluating the effectiveness of forest policy in Ontario to conserve biodiversity through emulation of natural disturbance. Recognizing that the full range and character of patterns created by natural disturbance cannot be implemented in managed forests due to practical constraints, but that management targets must be established, Rempel (2007) uses a multivariate statistical approach to identify a suite of forest songbirds whose habitat requirements encompass a range of conditions characteristic of natural landscapes. The species selected, based on multi-scale habitat models, are associated with local and landscape forest characteristics, including edge density, heterogeneity of the matrix, dominant overstory tree species, forest age and canopy closure; attributes that are also readily influenced by forest management. The methodology has substantial potential for broad application in generating testable hypotheses regarding the coarse-filter conditions necessary for sustaining communities of conservation concern in managed forests. In a parallel study, Rempel et al. (2007) apply the avian focal species bioassay in conjunction with spatially explicit forest simulation models to evaluate Ontario forest management policies that attempt to conserve biodiversity while maintaining current harvest levels. The scenario analyses are placed in context of natural disturbance by simulating the range of natural variation in forest composition and structure expected under wildfire and succession. The upshot of their assessment is 
that the boreal songbird community appears most resilient to the scenario that includes targets based on emulation of natural disturbance, which creates a diverse array of habitat conditions, and fares poorly when confronted with the current set of spatial guidelines used in Ontario, which tends to homogenize the forest. The authors offer a number of important qualifiers to these results, including model limitations and the need to better understand cause-and-effect relationships rather than simply habitat associations, as well as related measures of fitness. Nonetheless, the approach has considerable merit in forecasting the probable outcomes of alternative policies over relevant spatial and temporal scales, and exploring the parameter space within which resilience may be maintained. It also provides a foundation for adaptive management, the implementation of which is a measure of the adaptive capacity of institutions.

Lemelin et al. (2007) also evaluate the question of resilience from a community perspective, but in this case for waterfowl that breed in boreal forests. They use aerial survey data collected over a vast region of Quebec to compare waterfowl breeding-pair density before and shortly after clearcut logging of surrounding forests. Cavity-nesting ducks were predicted to be particularly vulnerable to forest harvesting due to nest-site limitation and the loss of cavity trees. However, they discover few differences in the response of ground-nesting and cavity-nesting species to the logging, and neither group exhibits significant, negative local effects on density, suggesting potential resilience of these groups to low levels of timber harvest. This qualifier is important, because the forests included in this study were, for the most part, undergoing a first episode of harvesting, thus very high levels of undisturbed forest remain. Longer-term effects of forestry could reduce the availability of large trees and natural cavities, and result in subsequent population declines. The authors also acknowledge that their use of density limits inferences regarding mechanisms underlying the response, and could mask other consequences of altered habitat conditions, such as changes in fitness. Nevertheless, the broad distribution of many of the ground-nesting waterfowl species, and wide variety of nesting habitats used, suggest that this group, in particular, may be resilient to timber harvesting. Of course, this has little to do with arguments based on adaptation to particular disturbance regimes.

The use of occupancy data to measure population response, and by inference resilience, is addressed directly by Hannah et al. (2008), who delve into forest-harvesting effects on one of the most abundant and ubiquitous boreal bird species, the White-throated Sparrow (Zonotrichia albicollis). Similar to Lemelin et al. (2007), they evaluate shortterm responses to conventional clearcutting, but in addition to measures of breeding density, they also present various indices of reproductive success. Whereas patterns in density suggest apparent resilience to local disturbance by clearcut harvesting, the poor reproductive performance of birds in recently logged Alberta sites suggests that longer-term population consequences could be significant. There is presently no indication of broad-scale population declines in White-throated Sparrows in the western boreal forests where this study was conducted, but several decades of decline have been observed in eastern portions of this species range, which also has a much longer history of forest harvesting. Interestingly, a comparison with similar reproductive indices from recently burned sites in Alberta reveals greater resilience to natural disturbance, suggesting that harvesting strategies that more closely emulate these patterns might help mitigate the negative effects of conventional, clearcut harvesting.

The boreal forests of Alberta also form the backdrop for an inter-regional comparison of life-history traits between populations of the same species occupying landscapes with different disturbance histories. Bélisle et al. (2007) challenge readers to consider whether the natural disturbance regime is a measurable evolutionary force with respect to morphological and behavioral characteristics. In order to evaluate this, they use data from translocation experiments and morphological comparisons to examine the vagility of the Ovenbird (Seiurus aurocapilla) in boreal mixedwood forests of Alberta and temperate deciduous forests of Quebec. They reason that the coarse-grained structure of boreal forests in Alberta, created by moderate to large fires, should select for a greater propensity for movement than the fine-grained structure of temperate forests in Quebec, which are dominated primarily by small-scale gap dynamics. Although the authors find little support for their hypothesis in Ovenbirds, they also identify a number of factors that confounded their study design. As a result, they do not dismiss the possibility that intraspecific differences in vagility might exist as a result of regional variation in disturbance regimes, and suggest approaches to 
testing this hypothesis in other species. The important contribution of this study is the presentation of a heuristic framework that formalizes the consideration of boreal landscape dynamics as an evolutionary force.

The final paper in our special section takes us to the eastern reach of boreal forests in Canada; the island of Newfoundland. Here, an impressive set of demographic data collected over a 4-year period is applied to the question of boreal songbird resilience in a study undertaken by Whitaker et al. (2008). Using mark-recapture techniques, the authors compare survival rates for adults of 14 species of songbirds between forest areas fragmented by either natural openings or recent clearcuts. They also explore the effect of life-history characteristics, including habitat affinity, migratory strategy, and the rate of transience in populations, on landscape differences. Although several species had lower breeding season survival in landscapes with clearcuts, their meta-analysis across all species suggests limited sensitivity to logging. However, overwinter survival was lower for 10 of 14 species in cut vs. natural landscapes. Overall, the variability in survival estimates was too high to be accounted for by mortality alone, prompting the authors to suggest that landscape-scale movements by adults may strongly influence boreal songbird population dynamics, and such adaptable movement behaviors may also confer resilience to local disturbances such as forest harvest. This suggestion is bounded by consideration of the range of spatial and temporal scales associated with natural and harvestinginduced landscape change. Furthermore, although many of the common species examined appear to be resilient to low levels of clearcutting (about 6\% of the landscape and $<15 \%$ of productive woodlands harvested), some species did experience negative effects. Whitaker et al. (2008) point out that, even with some resilience, adverse demographic effects and local extinctions may occur at higher levels of forest harvest. This is an important consideration in studies of resilience to forest harvesting in the Nearctic boreal forest. Responses to contemporary treatments may be misleading, as future harvest entries will substantially reduce the amount of older forest; in some cases, below the range of natural variability (see Cyr et al. 2009).

The papers in this special section provide an intriguing window into the world of boreal birds and their potential resilience to forest harvesting. Although diverse in scope, some common themes emerge. First, most studies were constrained by a short timeframe of sampling relative to the full implementation of forest harvesting in a given region. This reflects the relatively recent advent of large-scale logging in boreal forests of Canada. Second, the logging practices evaluated were not based on emulation of natural disturbance, except in one case through simulation. The stand structures and landscape patterns generally reflect traditional, multi-pass clearcut logging in its early stages. As a result, authors were careful not to under- or overstate the case for resilience, although most agreed with the premise based on first principles, and some results suggest that some adaptive capacity to landscape change induced by forest harvesting exists. Finally, the suite of studies emphasizes the diversity of requirements and responses of the boreal bird community in both natural and humanaltered landscapes, and the need for careful articulation of just what it means to say they are "resilient" to change, either individually or collectively.

It would be easy to close with a simple call for more research. However, in isolation, this would do little to support present forest planning and policy development. Despite the challenges of characterizing natural disturbance regimes (Cui and Perera 2008, Long 2009), it is clear that conventional "cut clear" clearcuts of relatively uniform size, arranged in checkerboard fashion across the landscape, have no ecological analog in boreal forests. Similarly, fixed targets applied universally across large landscapes will have an homogenizing effect that fails to capture the diversity of structures created by natural disturbances such as fire (e.g., Perera et al. 2009). Increased understanding of various parameters of forest disturbance, including frequency, size, and severity, is leading to the development of silvicultural strategies that more closely emulate natural disturbance at multiple spatial scales (Bergeron et al. 2002, 2006, Belle-Isle and Kneeshaw 2007). Some of these principles have already been implemented, with promising results for boreal birds (van Wilgenburg and Hobson 2008). As more of these strategies become realities, there will be many opportunities for research. With respect to the issue at hand, a critical role for science is to identify and communicate uncertainties regarding the "resilience hypothesis" and its application to boreal bird conservation; in particular, uncertainties that prevent selecting between policy options and management strategies. There remain many questions that could be 
addressed by exploiting the enormous variation in natural disturbance regimes across boreal forests of Canada; others that would benefit from an international perspective that includes boreal forests with a longer management history. There are also tremendous opportunities for scientists to encourage approaches that resolve or reduce uncertainties while actively managing systems (i.e., through adaptive management). We hope this special section inspires their pursuit.

Responses to this article can be read online at:

http://www.ace-eco.org/vol4/iss1/art4/responses/

\section{LITERATURE CITED}

Beisner, B. E., D. T. Haydon, and K. Cuddington. 2003. Alternative stable states in ecology. Frontiers in Ecology and Environment 1:376-382.

Bélisle, M., A. Desrochers, J.-F. Gobeil, and M.A. Villard. 2007. Are boreal Ovenbirds, Seiurus aurocapilla, more prone to move across inhospitable landscapes in Alberta's boreal mixedwood forest than in southern Québec's temperate deciduous forest? Avian Conservation and Ecology - Écologie et conservation des oiseaux 2(2): 1. [online] URL: http://www.ace-co.org/vol2/ iss $2 / \operatorname{art} 1 /$.

Belle-Isle, J., and D. Kneeshaw. 2007. A stand and landscape comparison of the effects of a spruce budworm (Choristoneura fumiferana (Clem.)) outbreak to the combined effects of harvesting and thinning on forest structure. Forest Ecology and Management 246:163-174.

Bergeron, Y., D. Cyr, C. R. Drever, M. Flannigan, S. Gauthier, D. Kneeshaw, È. Lauzon, A. Leduc, H. Le Goff, D. Lesieur, and K. Logan. 2006. Past, current, and future fire frequencies in Quebec's commercial forests: implications for the cumulative effects of harvesting and fire on age-class structure and natural disturbance-based management. Canadian Journal of Forest Research 36:27372744.

Bergeron, Y., A. Leduc, B. D. Harvey, and S. Gauthier. 2002. Natural fire regime: a guide for sustainable management of the Canadian boreal forest. Silva Fennica 36:81-95.
Berkes, F., J. Colding, and C. Folke, editors. 2003. Navigating social-ecological systems: building resilience for complexity and change. Cambridge University Press, Cambridge, UK.

Blancher, P. 2003. The importance of Canada's boreal forest to landbirds. Canadian Boreal Initiative, Ottawa, Ontario, Canada.

Carpenter, S., B. Walker, J. M. Anderies, and N. Abel. 2001. From metaphor to measurement: resilience of what to what? Ecosystems 4:765-781.

Cui, W., and A. H. Perera. 2008. What do we know about forest fire size distribution, and why is this knowledge useful for forest management? International Journal of Wildland Fire 17:234-244.

Cyr, D., S. Gauthier, Y. Bergeron, and C. Carcaillet. 2009. Forest management is driving the eastern North American boreal forest outside its natural range of variability. Frontiers in Ecology and the Environment (in press).

Drever, C. R., G. Peterson, C. Messier, Y. Bergeron, and M. Flannigan. 2006. Can forest management based on natural disturbances maintain ecological resilience? Canadian Journal of Forest Research 36:2285-2299.

Hannah, K. C., F. K. A. Schmiegelow, and K. E. H. Aitken. 2008. White-throated Sparrow response to forest harvesting in north-central Alberta: results not so clear-cut? Avian Conservation and Ecology - Écologie et conservation des oiseaux 3(1): 6. [online] URL: http://www.ace-eco.org/vol3/iss1/art6/

Lemelin, L. V., L. Imbeau, M. Darveau, and D. Bordage. 2007. Local, short-term effects of forest harvesting on breeding waterfowl and Common Loon in forest-dominated landscapes of Quebec. Avian Conservation and Ecology - Écologie et conservation des oiseaux 2(2): 10. [online] URL: http://www.ace-eco.org/vol2/iss2/art10/.

Long, J. N. 2009. Emulating natural disturbance regimes as a basis for forest management: a North American view. Forest Ecology and Management 257:1868-1873.

Perera, A. H., B. D. Dalziel, L. J. Buse, and R. G. Routledge. 2009. Spatial variability of stand-scale residuals in Ontario's boreal forest fires. Canadian Journal Forest Research 39:945-961. 
Puettmann, K. J., K. D. Coates, and C. C. 1661. Messier. 2009. A critique of silviculture: managing for complexity. Island Press, Washington, D.C., USA.

Rempel, R. S. 2007. Selecting focal songbird species for biodiversity conservation assessment: response to forest cover amount and configuration. Avian Conservation and Ecology - Écologie et conservation des oiseaux 2(1): 6. [online] URL: http://www.ace-eco.org/vol2/iss1/art6/.

Rempel, R. S., J. Baker, P. C. Elkie, M. J. Gluck, J. Jackson, R. S. Kushneriuk, T. Moore, and A. H. Perera. 2007. Forest policy scenario analysis: sensitivity of songbird community to changes in forest cover amount and configuration. Avian Conservation and Ecology - Écologie et conservation des oiseaux 2(1): 5. [online] URL:

http://www.ace-eco.org/vol2/iss1/art5/.

Schmiegelow, F. K.A., and M. Mönkkönen. 2002. Habitat loss and fragmentation in dynamic landscapes: avian perspectives from the boreal forest. Ecological Applications 12:375-389.

Walker, B., C. S. Holling, S. R. Carpenter, and A. Kinzig. 2004. Resilience, adaptability and transformability in social-ecological systems. Ecology and Society 9(2): 5. [online] URL: http://w ww.ecologyandsociety.org/vol9/iss2/art5/.

Whitaker, D. M., P. D. Taylor, and I. G. Warkentin. 2008. Survival of adult songbirds in boreal forest landscapes fragmented by clearcuts and natural openings. Avian Conservation and Ecology - Écologie et conservation des oiseaux 3 (1): 5. [online] URL: http://www.ace-eco.org/vol3/ iss1/art5/.

van Wilgenburg, S. L., and K. A. Hobson. 2008. Landscape-scale disturbance and boreal forest birds: can large single-pass harvest approximate fires? Forest Ecology and Management 256:136146.

Young, J., A. Watt, P. Nowicki, D. Alard, J. Clitherow, K. Henle, R. Johnson, E. Laczko, D. McCracken, S. Mitouch, J. Niemela, and C. Richards. 2005. Towards sustainable land use: identifying and managing the conflicts between human activities and biodiversity conservation in Europe. Biodiversity and Conservation 14:1641- 